\title{
Regionalization of Rainfall Intensity-Duration- Frequency (IDF) Curves With L-Moments Method Using Neural Gas Networks
}

Mohammadreza Mahmoudi ( $\sim$ m.mahmoudi@ag.iut.ac.ir)

Isfahan University of Technology https://orcid.org/0000-0002-3272-9870

\section{Saeid Eslamian}

Isfahan University of Technology

Saeid Soltani

Isfahan University of Technology

\section{Research Article}

Keywords: Intensity-duration-frequency (IDF), growing neural gas (GNG), neural gas (NG), Khozestan province

Posted Date: July 27th, 2021

DOI: https://doi.org/10.21203/rs.3.rs-699248/v1

License: (c) (i) This work is licensed under a Creative Commons Attribution 4.0 International License. Read Full License 


\section{Regionalization of Rainfall Intensity-Duration-Frequency (IDF)}

\section{Curves with L-Moments method using neural gas networks}

Author 1 (Corresponding author)

- Mohammad Reza Mahmoudi

- Department of Agriculture Engineering, Department of Water Engineering, Isfahan University of Technology, Isfahan, Iran

- ORCID: 0000-0002-3272-9870

- E-mail: m.mahmoudi@ag.iut.ac.ir

- $\quad$ Phone: (+98) 9138742903

Author 2

- Saeid Eslamian

- Department of Agriculture Engineering, Department of Water Engineering, Isfahan University of Technology, Isfahan, Iran

- E-mail: $\underline{\text { saied@iut.ac.ir }}$

Author 3

- $\quad$ Saeid Soltani

- Department of Natural Resources Engineering, Isfahan University of Technology, Isfahan, Iran

- E-mail: ssoltani@cc.iut.ac.ir 


\begin{abstract}
Floods are one of the most frequent and destructive natural events which lead to lots of human and financial losses with damage to the houses, farms, roads, and other buildings. Intensity-duration-frequency (IDF) curves are the main and practical tools that have been used for flood control studies including the design of the water structures. In many cases, there is not any measuring device at the desired place or their information are not useful if there is any available. In this case, it is not possible to extract these curves through the conventional methods. Regionalizing the IDF curves is a method that has solved the issues mentioned in the common methods. In this research, the regionalized IDF curves are extracted in Khozestan province, Iran using 21 rain gauge stations through L-moments and neural gas networks. Clustering is one of the most effective steps and a prerequisite for regional frequency analysis (RFA) that divides the region and existing stations into hydrologically homogenous regions. In this study, clustering is done using two new models named neural gas (NG) and growing neural gas (GNG) network. Comparing the regional IDF curves with single site curves, it was found that neural gas network models had a more accurate performance and higher efficiency so that they had the lowest estimate error amount among other models. Also, due to the acceptable difference between regional and single site curves, the efficiency of L-Moments in RFA was evaluated as appropriate.
\end{abstract}




\section{Introduction}

Intensity-duration-frequency (IDF) curve is one the most common tools in water resources engineering which can be used as an input in planning and designing, and exploitation of water resources projects. One of the common problems in many countries is the scattered or very weak networks of the required meteorological stations such that their data are considered as main bases for IDF construction. To this problem, a regional analysis of rainfall depth and building the IDF curves has been proposed.

The IDF concept refers to the Bernard's efforts in 1932 and a lot of the studies focused on improving the statistical inference methods used in IDF (Bell 1969). One of the noticeable researches in this field is Hasking and Wallis' study (1997) on developing a method for Lmoments estimation, probability-weighted moments (PWM)(Greenwood et al. 1979), parametric formulation of IDF relations (Koutsoyiannis et al. 1998) and employing the regional methods like the Index-Flood method.

Today Atlas of IDFs has been built in developed countries. One of the works is the National Oceanic and Atmospheric Administration (NOAA) atlas 14 which was created by American National Weather Services at ( Perica et al. 2013).

Regional analysis uses the group statistics and characteristics from co-behavioral stations instead of using data only from one station. Several studies using regional methods on the extreme rainfalls suggest that these techniques increasingly reduce the doubts on the estimates resulted from the at-site view of point (Lee et al. 2003)One of the main problems to expand frequency analysis results from one or more stations to one region is the hydrological lack of homogeneity of the region. Despite the suitability of cluster analysis for grouping the hydrological features, homogeneity of the regions is not completely achieved. So it is 
recommended to examine and test the cluster analysis results with the other coventional methods (Rousseeuw 1987)

Soltani et al. (2017) using the characteristics of rainfall time scale and three variables of average daily rainfall intensity, the standard deviation of daily rainfall intensity, and scale index, drew the regional IDF curves for Khozestan province and the absolute error of estimates for this method was mainly beelow $25 \%$ and confirmed the results were acceptable.

Using topographic and rainfall characteristics, Alemaw et al. (2016) divided Botswana into three hydrologically homogeneous regions using the K-Means clustering model. They also used both gamma and lognormal probability distribution to estimate the depth of rainfall at the return periods up to 100 years for the mentioned areas.

Amin and Shaaban (2004) used generalized extreme values distribution(GEV) and extreme values distribution (EV1) with least square method in the estimation of distribution parameters for the IDF curves in Peninsular of Malaysia.

The IDF Regionalizion is very beneficial in terms of shortening the steps and required time to perform the calculations as well as providing it for the area and not only for the station.

Identifying the homogeneous regions is usually the most crucial and difficult step and a prerequisite for the frequency analysis hypotheses between the hydrologic frequency analysis stages of the region. In this study, a method based on the neural gas and growing neural gas networks is presented to cluster the hydrological data and determine the homogeneous regions. The neural gas network is one of the types of competitive neural networks and uses an unsupervised teaching method. The network was first introduced by Martinez and Schulten (1991). One of the features of this algorithm is learning the topology or distribution shape of the data space. One of the issues with this algorithm is that it starts working with the several elements which makes the algorithm too slow at first. This problem was solved four years later 
when the growing neural gas network was presented by Fritzk (1995). The number of neurons in the growing neural gas network is increasing during the learning process regardless of prior knowledge and the governing structure of the inputs.

Abdi et al. (2017) investigated the ability of the growing neural gas network to regionalize the drought index for 40 synoptic stations in Iran and the results of the heterogeneity evaluation based on L- moments showed the success of this algorithm compared to the other methods in determining the homogeneous sub-regions.

The application of neural gas networks in clustering has also been considered in other scientific disciplines such as robotics(Carlevarino et al. 2000; Ferrer 2014), medicine(Cselényi 2005; Oliveira Martins et al. 2009; Angelopoulou et al. 2015), and economics(Decker 2015; Lisboa et al. 2000). Therefore, this algorithm can be used for clustering as well as an image segmentation.

To date, no studies have been conducted to regionalize the IDF curves using clustering based on neural gas networks. Also in the field of hydrology and water resources, neural gas networks have not been used so far except for a few cases(Abdi et al. 2017).

After using neural gas networks and other models for clustering, it is required to investigate the formed regions and stations in each area in terms of homogeneity and discordancy. For this purpose, Husking and Wallis tests, which are based on L-moments are known as the best method for the regional analysis.

67 L-moments were presented by Husking (1990) and it has been found the great importance and application in many regional analyzes. The most crucial applications of L-moments include detecting the homogeneous regions, determining the discordant stations, selecting the appropriate distribution function, and estimating the parameters of distribution functions 
that they can describe a larger range of distributions and the estimates have the less bias. They also work better at displaying the outlier events (Rao and Hamed 1997).

In this study, both two models of neural gas networks have been used to regionalize the IDF curves in Khozestan province. The results were then compared using a test based on Lmoments combining the conventional clustering models like Ward, K-Means, $\operatorname{SOM}^{1}$, and $\mathrm{FCM}^{2}$. The IDF regional curves were also extracted with the L-moment concepts.

Several studies with the L-Moments method have analyzed the frequency of extreme rainfalls and extracted the appropriate distribution function for each region. For instance, Young et al. (2010) divided the Pearl river basin in China into 6 homogeneous clusters and they performed the regional frequency analysis for maximum annual 1,3, 5, and 7 days rainfall with L-moments. The goodness of fit tests showed that the distribution functions of PE3 ${ }^{3}$, $\mathrm{GLO}^{4}$, and GEV fit well in the most areas in the homogeneous regions.

Kisley et al. (2007), Jingley and Hall (2004), Kejeldson et al. (2002) studies in the application of statistical methods, have confirmed L-moments and showed that PWMs and Lmoments are preferred to the raditional estimation methods, especially for the regional studies. regional IDFs for the Malaysian Peninsular region and evaluated the application of this method due to the associated simplicity as well as its efficiency in areas without the suitable stations. frequency analysis of maximum monthly rainfall in the Isfahan region, Iran with their single- 
92 site values. They described the L-Moments method as an accurate and useful tool for confirming the similarities or differences in regional rainfall frequency analysis.

\section{Study area and data}

In this study, data were provided from 21 rain gauge stations located in Khozestan province,

Iran by Province Water and Electricity Organization. The minimum record length related to

Payepol station with 16 years and the maximum record length related to Ahwaz stations and

Shohada dam with 42 years (Table 1). The data used to determine the number of optimal clusters and also the input data to clustering models include the geographical latitude and

100 longitude variables, height from sea level, maximum average precipitation (MAP), maximum

101 daily precipitation (MDP), annual rainfall average for each station which has been shown in

102 table 1 . Khozestan province which covered $4 \%$ of the total area of the country is the largest in

103 the western half of the country. This province is located between $47^{\circ} 41^{\prime}$ to $50^{\circ} 39^{\prime}$ east longitude 104 and $29^{\circ} 58^{\prime}$ to $33^{\circ} 04^{\prime}$ north of the equator. Despite having only $4 \%$ of the total area of the

105 country, this province owns more than $30 \%$ of the surface water of the country. The geographic 106 location of the province and stations are shown in figure1.

\section{3. Methodology}

108 In this section, a suggested method to extract the IDF regional curves has been explained, 109 which the steps are as follows:

1101 - Determining the number of optimal clusters using hydrologic data provided in Table 1.

1112 - Implementation of neural gas networks and other common models mentioned in order to 112 the clustering.

113 3-Investigate the homogeneity of the formed regions and the discordance of the stations in 114 each region. 
115 4- Determine the appropriate statistical distribution for each region and estimate the 116 distribution parameters at the required duration.

117 5- Investigate the quantiles or amounts of precipitation in duration and the required return 118 periods.

119 6- Draw the regional IDF curves.

$120 \quad$ 3.1. Neural Gas (NG) network

121 The rule of learning in the neural gas network is as follows: assumed as a value and eventually, it is revised to have the logical and optimal function of the algorithm. These elements also have been selected in the main data range. $\alpha_{i}$ is a parameter that specifies the learning rate and depends on $k_{i}$ and $\lambda$. as if $\lambda$ tends to infinity, learning of the

128 whole neurons would be equal and if it tends to zero, then the nearest neuron begins to learn.

129 The extreme modes of $\lambda$ are not suitable alone and usually, a mode between them is chosen.

$130 k_{i}$ refers to the superior neuron to the i neuron. $\varepsilon$ is also a constant number that controls the 131 learning rate.

132 To create a neighborhood between the first and second neurons in terms of proximity, an 133 edge is created. For each neuron there is $c_{i . j} \in\{0.1\}$ which shows that there exists an edge or 134 neighborhood or doesn't exist and also $t_{i . j} \in\{0.1 .2 \ldots$.$\} which shows the time intervals (age)$

135 from the last meeting or re-edge, that if it exceeds more than one size, the neighborhood will 136 be broken. This approach helps the neural network to learn topology.

137 NG algorithm can be summarized as follows: 
138 Step 1: A random position of $w_{i}$ is created in the data space.

139 Step 2: An input named $\mathrm{x}$ is selected from the expected data.

140 Step 3: Aging, which includes computation of the distance between $\mathrm{x}$, and the centers of $w_{i}$, 141 and $k_{i}$ aging for each center.

142 Step 4: Adaption or learning.

$$
w_{i}^{\text {new }}=w_{i}^{\text {old }}+\varepsilon e^{\frac{-k_{i}}{\lambda}}\left(x-w_{i}^{\text {old }}\right)
$$

144 The main point is that during the training period, as the algorithm progresses, the learning speed should be reduced, otherwise the neural network will be repeated and an incorrect cycle

146 will be created. For this purpose, the amount of $\lambda$ and $\varepsilon$ should be decreases as learning 147 progresses. So, the following function would be used.

$$
\mathrm{G}(\mathrm{t})=G_{i}\left(\frac{G_{f}}{G_{i}}\right)^{\frac{t}{t_{\max }}}
$$

$$
\lambda_{i}>\lambda_{f}, \quad \varepsilon_{i}>\varepsilon_{f}, \quad T_{i}<T_{f}
$$

150 Where $\mathrm{i}$ index shows the parameter value at the beginning of learning and $\mathrm{f}$ index shows the 151 value of the parameter at the end of the learning process. For instance, if $\mathrm{t}=0$, so $\lambda(t)=\lambda_{i}$, and if $t=t_{\max }$, so $\lambda(t)=\lambda_{f}$

153 Step 5: An edge between the first two ranks in terms of proximity and age of this edge is 154 considered equal to zero (create a neighborhood).

Step 7: It is assumed that $k_{i}=0$ and for each $\mathrm{j}$ which is $t_{i . j}>T$, it is considered as $c_{i . j}=0$. at this step for the reasons mentioned in step 4, T should be increased during the learning period to reduce the degree of rigidity, which means the edges are allowed to last longerStep 8: If the 
159 termination conditions are not met (for example, the maximum quantity of neurons or any

160 amount of performance) the step2 is repeated. Otherwise, algorithm steps would be finished.

161

162

163

164

165

166

167

168

169

170

171

172

173 GNG algorithm can be summarized as given below:

$174 \quad$ Step1: Creating two random neurons at locations $w_{1}$ and $w_{2}$

175 Step 2: Select vector input called $\mathrm{x}$

176 Step 3: Finding the best neuron $\left(s_{1}\right)$ and second-best neuron $\left(s_{2}\right)$

177 Step 4: Increasing age of all edges connected to $s_{1}$

178

179

Step 5: Increase the amount of accumulated error in $s_{1}$

180

\subsection{Growing neural gas (GNG) network} similar to the input data set(Morell et al. 2014).

$\forall_{j}: t_{s_{1} j} \leftarrow t_{s_{1} j}+1$

GNG algorithm, which is based on the unsupervised artificial neural networks, was first introduced by Fritzk (1995). The GNG network is a clustering algorithm that is working step by step, it means that the number of neurons is increasing without using a previous knowledge about the structure of input patterns during the learning process (Fink et al. 2015). Unlike classical clustering algorithms, the GNG algorithm owns a compatible network structure which makes it suitable for learning the large data set topologies (Zaki and Yin 2008). The main idea of GNG is that it will continuously add the new nodes (neurons) to a small initial network in a growing structure. In the GNG network, the neurons compete to determine which one is most

$$
E_{S_{1}}=E_{S_{1}}+\Delta E_{S_{1}}
$$




$$
\Delta E_{s_{1}}=\left\|w_{s_{1}}-x\right\|^{2}
$$

181

Step 6: Adaptation

$$
\begin{gathered}
w_{s_{1}}^{\text {new }}=w_{s_{1}}^{\text {old }}+\varepsilon_{b}\left(x-w_{s_{1}}^{\text {old }}\right) \\
w_{n}^{\text {new }}=w_{n}^{\text {old }}+\varepsilon_{n}\left(x-w_{n}^{\text {old }}\right) \\
\varepsilon_{b}>\varepsilon_{n}
\end{gathered}
$$

182 Step 7: Creating an edge between $s_{1}$ and $s_{2}$ if there is not any.

$183 \quad C_{s_{1} s_{2}}=1 . \quad t_{s_{1} s_{2}}=0$

184 Step 8: All edges that their age is more than T, will be deleted.

185

$$
t_{i j}>T \rightarrow C_{i j}=0
$$

186 Step 9: If the number of inputs presented to the network is an integer multiplier of L, a new

187 neuron is created. This neuron is created at the location of $w_{r}$.

$$
\begin{gathered}
w_{r}=\frac{1}{2}\left(w_{q}+w_{f}\right) \\
C_{f q}=0 . C_{r f}=C_{r q}=1
\end{gathered}
$$

$188 \mathrm{q}$ is the neural index which has the most amount of accumulated error, $\mathrm{f}$ is the neighbor 189 index of q which has the most errors.

$190 \quad E_{f}$ and $E_{q}$ errors with $\alpha$ coefficient are declined:

191

$$
E_{f} \leftarrow \alpha E_{f} . \quad E_{q} \leftarrow \alpha E_{q} \quad \alpha<1
$$

192 Consider error $E_{r}$ equals to $E_{q} . \quad E_{r}=E_{q}$

193 Step 10: Decreasing the accumulated error of all neurons. $\quad E_{i} \leftarrow d E_{i} \quad d<1$ 

performance) has not yet been met, step1 would be repeated. calculated using the below relations.

$$
\begin{gathered}
u_{i}=\left[t^{(i)} \cdot t_{3}^{(i)} \cdot t_{4}^{(i)}\right]^{T} \\
\bar{u}=\frac{1}{N} \sum_{i=1}^{N} u_{i} \\
s=(N-1)^{-1} \sum_{i=1}^{N}\left(u_{i}-\bar{u}\right)\left(u_{i}-\bar{u}\right)^{T} \\
D_{i}=\frac{1}{3}\left(u_{i}-\bar{u}\right)^{T}\left(u_{i}-\bar{u}\right) S^{-1}
\end{gathered}
$$

Where $u_{i}=\left[t^{(i)} \cdot t_{3}^{(i)} \cdot t_{4}^{(i)}\right]^{T}$ is the L-Moment ratio Matrix in station $\mathrm{i}, \mathrm{N}$ is the number of 202 stations and $\mathrm{S}$ is the sample covariance matrix.

If $D_{i}$ is big, the location $\mathrm{i}$ is discordant. An appropriate criterion to determine if a station is 204 discordant or not is that $D_{i}$ is bigger than 3 or equal to it.

To calculate the degree of heterogeneity first $V_{1}$ would be obtained using equation 14 for 206 the observed data.

$$
\begin{aligned}
\mathrm{V}_{1} & =\sum_{\mathrm{i}=1}^{\mathrm{N}} \mathrm{n}_{\mathrm{i}}\left(\mathrm{t}^{(\mathrm{i})}-\overline{\mathrm{t}}\right)^{2} / \sum_{\mathrm{i}=1}^{\mathrm{N}} \mathrm{n}_{\mathrm{i}} \\
\overline{\mathrm{t}} & =\left(\sum_{\mathrm{i}=1}^{\mathrm{N}} \mathrm{N}_{\mathrm{i}} \mathrm{t}^{(\mathrm{i})}\right) /\left(\sum_{\mathrm{i}=1}^{\mathrm{N}} \mathrm{n}_{\mathrm{i}}\right)
\end{aligned}
$$


207 Where $n_{i}$ is the size of samples in the station $\mathrm{i}, \mathrm{t}^{(\mathrm{i})}$ is the sample L-moment (L-CV), $\bar{t}$ is the 208 point average of sample moment (L-CV).

209 For each simulated area, $\mathrm{V}_{1}$ would be calculated. Also from simulated data, average $\mu_{v}$ and 210 standard deviation $\sigma_{v}$ and inhomogeneity criterion would be determined through relation 16.

211 Husking and Wallis (1991) suggested that an area can be an acceptable homogenous area if

$212 \mathrm{H}_{\mathrm{i}}$ is smaller than 1 and it can be relatively hetrogenous if $\mathrm{H}_{\mathrm{i}}$ is between 1 and 2 and it would 213 be definitely hetrogenous if $\mathrm{H}_{\mathrm{i}}$ is bigger than 2. In practice, the $\mathrm{H}_{1}$ criterion is more appropriate 214 (Rao and Srinivas 2006).

\subsection{Selecting the appropriate distribution}

217 Selecting an appropriate frequency distribution for homogeneous regions can be done by 218 comparing the distribution moments with the average regional moment of the data. Also, to 219 select the best distribution, a goodness of fit test will be performed for the distribution function.

220 This test would be done through calculation statistics of $Z^{\text {Dist }}$. An appropriate distribution

221 function is a function which is $\left|Z^{\text {Dist }}\right|<1.64$

$$
\begin{aligned}
& Z^{\text {Dist }}=\left(\tau_{4}^{\text {Dist }}-\bar{\tau}_{4}+\beta_{4}\right) / \sigma_{4} \\
& \beta_{4}=N_{\text {sim }}^{-1} \sum_{m=1}^{N_{\text {sim }}}\left(\bar{\tau}_{4 m}-\bar{\tau}_{4}\right) \\
& \sigma_{4}=\left\{\left(N_{\text {sim }}-1\right)^{-1} \sum_{m=1}^{N_{\text {sim }}}\left(\bar{\tau}_{4 m}-\bar{\tau}_{4}\right)^{2}-N_{\text {sim }} \beta_{4}^{2}\right\}^{1 / 2}
\end{aligned}
$$


224 the areal average of L-moment sample kurtosis , $\beta_{4}$ the area bias value of the above moment, $225 \sigma_{4}$ is the regional deviation of the above moment, and $\mathrm{N}_{\text {sim }}$ is the number of simulated areas.

\subsection{Regionalization of IDF curves} region with the $N_{s}$ stations are shown by $Q_{j}$. Rainfall observation data, $x_{j}$ for the station in specified quantiles, $\mathrm{T}$ would be calculable through equation 20 . So rainfall data sets in the station $\mathrm{j}$ can be calculated as follows:.

$$
\begin{gathered}
x_{j . k}=Q_{j}\left(T_{k}\right) \\
k=1 \ldots n_{j} \cdot j=1 \ldots N_{S}
\end{gathered}
$$

231 If the area is homogeneous, the set of quantiles for the station $\mathrm{j}$ will be as per equation 21 .

$$
\mathrm{T}=2,5,10,20,50,100 \quad \mathrm{j}=1, \ldots, \mathrm{n} \quad Q_{j}(T)=\mu_{j} X_{T}
$$

In equation $21, \mathrm{X}_{\mathrm{T}}$ is a set of dimensionless regional quantile with a probability of not exceeding $f$ which is called the regional growth curve. $\mu_{j}$ is the scale factor for station $i$, that parameters such as mean or median are considered to simplify the calculations.

The value of variation coefficient moment and ratios of L-moments for the station $\mathrm{j}$ using single site data, $\mathrm{x}_{\mathrm{j}}$, is equal to their amounts for regional data. As a result, it will be possible to estimate the regional quantiles $\mathrm{X}$, by equating the first to fourth moments of the region with the mean, the coefficient of variation moments, and the L-moments ratios of the distribution function considered for the region. each duration and the desired return period in a homogeneous region, along with estimating 
242 the scale factor $\mu_{j}$, for only one station in the region, different values ( $\mathrm{i}, \mathrm{d}, \mathrm{T}$ ) using equations

243 (20) and (21) will be computable. So it is not needed to estimate the probability of distribution

244 function for every single annual series in each station. Finally, using these values, a regional

245 IDF curve will be drawn for each homogeneous region.

246 To investigate the differences between the regional IDF curves which are based on the

247 regional distribution functions with the stationary IDF curves, three equations of the 248 Coefficient of Variation of Root Mean Square Error ( $\left.\mathrm{CV}_{\mathrm{RMSE}}\right)$, Mean Percentage Difference $249(\Delta)$, and Mean Bias Error (MBE) as per below were used. The lower the $\mathrm{CV}_{\mathrm{RMSE}}$ and $\Delta$ values, 250 the more accurate the model used in clustering. Also, the negative MBE values indicate 251 overestimation, and the positive values indicate an underestimation of the regional values than 252 the at-station rainfall values.

$$
\begin{gathered}
C V_{R M S E}=\frac{\sqrt{\frac{1}{N_{d} N_{T}} \sum_{d=1}^{N_{d}} \sum_{T=1}^{N_{T}}\left(x_{d . T}-z_{d . T}\right)^{2}}}{\frac{1}{N_{d} N_{T}} \sum_{d=1}^{N_{d}} \sum_{T=1}^{N_{T}} x_{d . T}} \times 100 \\
\Delta=\frac{1}{N_{d} N_{T}} \sum_{d=1}^{N_{d}} \sum_{T=1}^{N_{T}} \frac{\left|x_{d . T}-z_{d . T}\right|}{x_{d . T}} \times 100 \\
M B E=\frac{\sum_{d=1}^{N_{d}} \sum_{T=1}^{N_{T}}\left(x_{d . T}-z_{d . T}\right)}{N_{d} N_{T}}
\end{gathered}
$$

253 In the above relations $\mathrm{x}_{\mathrm{d} . \mathrm{T}}$ and $\mathrm{z}_{\mathrm{d} . \mathrm{T}}$ are respectively maximum rainfall intensity in duration $254 \mathrm{~d}$ and the return period $\mathrm{T}$ in the specified station and the homogeneous area in which the station 255 is located. Also, $\mathrm{N}_{\mathrm{d}}$ and $\mathrm{N}_{\mathrm{d}}$ are the number of durations and return periods.

\section{Results}

4.1. Cluster Analysis 
Used data sets should be normalized before entering the clustering models. This is due to the existence of data from the different types such as geographical data as well as precipitation data, which also has the different units. Based on these normalized data, probabilistic homogeneous regions were determined using clustering models including the new method of neural gas networks and the common models of Ward, K-means, Self-Organizing Map, and Fuzzy C-means

CS(Chou et al. 2004), Silhouette, and Calinski-Harabasz (1974) indices were used to determine the optimal number of clusters. Figures 2 to 4 shows the number of optimal clusters in a range of clusters. Since the highest value in Silhouette and Calinski-Harabasz indices and the lowest value in CS indicate the number of optimal clusters, the number of region in all three models is equal to 2 .

The output of clustering models based on two separate regions in the specified area which shows the way of dividing stations between these two regions is shown in figures 5 to 8 . As it is known that the result of clustering for some stations is different in several models which is due to the differences in the performance of each model. The Ward, SOM, and K-Means models have been shown the same performance which can be seen in figure 8 . Also, region 1 occupies more eastern areas and region 2 occupies the central and western areas of the province. According to the height index of each station, the results show that the stations with the higher altitudes in the eastern cluster and the lower stations in the western cluster are divided which confirms the proper functioning of neural gas networks in terms of topographic detection of 280 the data space.

The fixed parameters used in both neural gas and growing neural gas networks are presented in table 2.

\subsection{Regional homogeneity tests}


To investigate the regional homogeneity and discordancy of the stations in each region, the

$285 \mathrm{H}$ and $\mathrm{D}_{\mathrm{i}}$ statistics, which are tests based on L-moments, were used, respectively. These values were determined for the maximum intensity of annual rainfall at the different duration as well as the various models used for clustering. These results are presented for 24-hour rainfall in table 3. Referring to the results, in none of the applied clustering models in different time duration, there was not any discordant station and except for a few cases, all of the regions formed in different models were homogeneous, which indicates the appropriate accuracy of the clustering models used.

According to the results of the goodness of fit test, the generalized logistics distribution(GLOG) and GEV distribution are selected as the regional distribution function for regions 1 and 2, respectively. To estimate the required quantiles, it is necessary to calculate the parameters of regional distribution. For this purpose, in all of the used clustering models, the first to fourth moments of both generated regions are considered equal to the first to fourth moments of distribution function considered for the region. The results for the neural gas network model(NG) are presented as an instance in table 4.

To determine the best clustering model, the numerical values of regional curves with the 300 same values in stationary curves were compared and the results are presented in table 5. As can 301 be seen from table 5, according to the calculated estimate error values, the neural gas network clustering model has the lowest error amount in both indicators, which shows the superiority of this method over the other methods. Also, the negative MBE index for this model indicates

304 that the numerical values of the regional IDF curves obtained from this method are somewhat 305 larger than the at-station values (overestimation). Also by considering all of the three 306 indicators, the growing neural gas network can be considered as the second suitable model. By

307 considering the error values between the regional IDF with at-station IDF which are presented 308 in table 6 , it is concluded that in stations with the short record length, the estimate error amount 
has been increased, and if this station would be removed, the better performance can be expected from

310 the used clustering models The comparison between the two types of regional and at-site curves in the

311 four selected stations is shown in figure 9.

\section{Conclusions}

313 In this study, two new models of neural gas and growing neural gas networks were presented

314 to regionalize the IDF curves. For this purpose, taking into account the characteristics of

315 longitude, latitude, average annual rainfall, altitude, and maximum 24-hour annual rainfall for 316 each station, and using 3 indicators of and CS, Silhouette, and Calinski-Harabasz $(\mathrm{CH})$, it has

317 been determined that Khozestan province has two separate and possibly homogenous regions.

318 Then, using different clustering models, the homogeneous regions have been formed.

319 Clustering was one of the most important and main steps of this research due to the associated sensitivity and great impact on the final result. Therefore, clustering operations were performed using 6 different models, Ward, K-means, FCM, Self-Organizing Map (SOM), that are among the most widely used methods. In addition to the four methods mentioned, two new models of the neural gas network (NG) and growing neural gas network (GNG) were used for clustering.

To investigate the homogeneity of the two regions, as well as the discordancy of the stations in each region, in all of the 6 models in eleven durations, the regional homogeneity tests and discordancy tests based on L-moments were used. In most models and different durations, the regions created by clustering had a good homogeneity. After determining the position of each station in the dual regions and identifying both areas as homogeneous, the regional distribution function was determined and then the regional IDFs were extracted using the L-moments method. The regional IDF curve obtained for each area was compared with the at-station IDF

331 curves in the same area. The results showed that in all of the stations, the regional and stationary

332 IDF curves are highly consistent and show the same trend. This research is the first one to 333 evaluate the efficiency of neural gas networks in regionalizing the IDF curves. Among 
extracted regional IDFs, the curves obtained from the region composed of neural gas networks and growing neural gas network models had the highest accuracy and the most compliance

336 with the at-station curves, which indicates the efficiency of these models in terms of 337 regionalization. The quality of operation of neural gas networks can improve the various issues 338 and problems related to the water resources management and planning.

\section{$339 \quad$ Acknowledgement}

340 The authors appreciate the constructive comments of anonymous reviewers on this paper,

341 which helped improve the final version of the paper.

\section{$342 \quad$ Availability of data and material}

$343 \quad$ Not applicable.

\section{$344 \quad$ Code availability}

$345 \quad$ Not applicable.

\section{$346 \quad$ Author's contributions}

347 All authors collaborated in the research presented in this publication by making the

348 following contributions: research conceptualization, Mohammad Reza Mahmoudi (M.R.M.),

349 Saeid Eslamian (S.E.), Saeid Soltani (S.S.); methodology, M.R.M., S.E., and S.S.; formal 350 analysis, M.R.M, and S.E; writing—original draft preparation, M.R.M; writing—review and 351 editing, M.R.M, S.E.; supervision, S.E.

$352 \quad$ Funding

353 This research received no external funding.

354 Declarations

\section{Ethics approval}


We confirm that this article is an original research and has not been published or presented previously in any journal or conference in any language.

\section{$358 \quad$ Consent to participate}

$359 \quad$ Not applicable.

\section{$360 \quad$ Consent for publication}

361 All the authors consented to publish the paper.

$362 \quad$ Conflict of Interest

363 The authors declare that they have no conflict of interest.

\section{$364 \quad$ References}

Abdi A, Hassanzadeh Y, Ouarda TB (2017) Regional frequency analysis using Growing Neural Gas network. J Hydrol 550: 92-102.

Alemaw BF, Chaoka RT (2016) Regionalization of Rainfall Intensity-DurationFrequency (IDF) curves in Botswana. J Water Resour Prot 8(12): 1128.

Amin MZ, Shaaban AJ (2004) The rainfall intensity-duration-frequency (IDF) for storm events. Int J Math Comput Sci 10: 217-223. 
Bell FC (1969) Generalized rainfall-duration-frequency relationships. Journal Hyd Div. 95: 311-327.

Bernard MM (1932) Formulas for rainfall intensities of long duration. Trans Am Soc Civil Eng 96(1): 592-606.

Caliński T, Harabasz J (1974) A dendrite method for cluster analysis. Commun Stat 3(1): 1-27.

Carlevarino A, Martinotti R, Metta G, Sandini G (2000) An incremental growing neural network and its application to robot control. Proceeding of the International Joint Conference on Neural Networks, Como, Italy, Jul. 24-27, pp. 323-328.

Chou CH, Su MC, Lai E (2004) A new cluster validity measure and its application to

Fink O, Zio E, Weidmann U (2015) Novelty detection by multivariate kernel density 
Fritzke B (1995) A growing neural gas network learns topologies. Neur Inf PR Sys 7:625-

402 632.

403

Greenwood JA, Landwehr JM, Matalas NC, Wallis JR (1979) Probability weighted

404 moments: definition and relation to parameters of several distributions expressable in inverse form. Water Resour Res 15: 1049-1054.

Hosking JR (1990) L-moments: Analysis and estimation of distributions using linear combinations of order statistics. J R Stat Soc 52: 105-124.

408

Hosking J, Wallis J (1993) Some statistics useful in regional frequency analysis. Water 409 Resour Res 29: 271-281.

Hosking JR, Wallis JR (2005) Regional frequency analysis: an approach based on Lmoments. Cambridge University Press, USA.

Jingyi Z, Hall M (2004) Regional flood frequency analysis for the Gan-Ming River basin in China. J Hydrol 296: 98-117.

Kjeldsen TR, Smithers J, Schulze R (2002) Regional flood frequency analysis in the KwaZulu-Natal province, South Africa, using the index-flood method. J Hydrol 255: 194-211.

Koutsoyiannis D, Kozonis D, Manetas A (1998) A mathematical framework for studying rainfall intensity-duration-frequency relationships. J Hydrol 206: 118-135.

Kyselý J, Picek J, Huth R (2007) Formation of homogeneous regions for regional frequency analysis of extreme precipitation events in the Czech Republic. Stud Geophys Geod 51: 327-344. 
Lee SH, Maeng SJ (2003) Frequency analysis of extreme rainfall using Lmoment. Irrigation and Drainage: The journal of the International Commission on Irrigation and Drainage 52(3): 219-230.

Lisboa PJ, Edisbury B, Vellido A (2000) Business applications of neural networks: the state-of-the-art of real-world applications. World Scientific Publishing Company. Singapore.

Martinetz T, Schulten K (1991) A" neural-gas" network learns topologies. Artificial Neural Network 1: 397-402.

Morell V, Cazorla M, Orts-Escolano S, Garcia-Rodriguez J (2014) 3d maps

Oliveira Martins L, Silva AC, De Paiva AC, Gattass M (2009) Detection of breast masses in mammogram images using growing neural gas algorithm and ripley's k function. J Signal Process Syst 55(1): 77-90.

Perica S, Martin D, Pavlovic S, Roy I, Laurent MS, Trypaluk C, Unruh D, Yekta M, Bonnin GJ (2013) Precipitation-frequency Atlas of the United States 14. American National Weather Services.

Rao AR, Hamed KH (1997) Regional frequency analysis of Wabash River flood data by L-moments. J Hydrol Eng 2: 169-179.

Rao AR, Srinivas V (2006) Regionalization of watersheds by hybrid-cluster analysis. J Hydrol 318: 37-56. cluster analysis. J Comput Appl Math 20: 53-65. 
Soltani S, Helfi R, Almasi P, Modarres R (2017) Regionalization of rainfall intensityduration-frequency using a simple scaling model. Water Resour Manag (13): 42534273.

Wallis JR (1982) Hydrologic problems associated with oilshale development. Environ Sys Manag edited by S. Rinaldi 85-102.

Yang T, Shao Q, Hao ZC, Chen X, Zhang Z, Xu CY, Sun L (2010) Regional frequency analysis and spatio-temporal pattern characterization of rainfall extremes in the Pearl River Basin, China. J Hydrol 380: 386-405.

Zaki SM, Yin H (2008) A semi-supervised learning algorithm for growing neural gas in 454 face recognition. J Math Model Algorithms 7: 425-435. 


\section{Figure captions}

Figure 1. Map of the study area with location of the rainfall stations.

Figure 2. Calinsky-Harabasz values versus the number of clusters.

Figure 3. Sillhouette values versus the number of clusters.

Figure 4. CS values versus the number of clusters.

Figure 5. Location of stations in the cluster identified by NG.

Figure 6. Location of stations in the cluster identified by GNG.

Figure 7. Location of stations in the cluster identified by SOM, K-Means, and Ward methods.

Figure 8. Location of stations in the cluster identified by FCM methods.

Figure 9. IDF curves for four rainfall stations in Khozestan province (Note: The values on each curve is the return period $\mathrm{T}$ for the curve). 


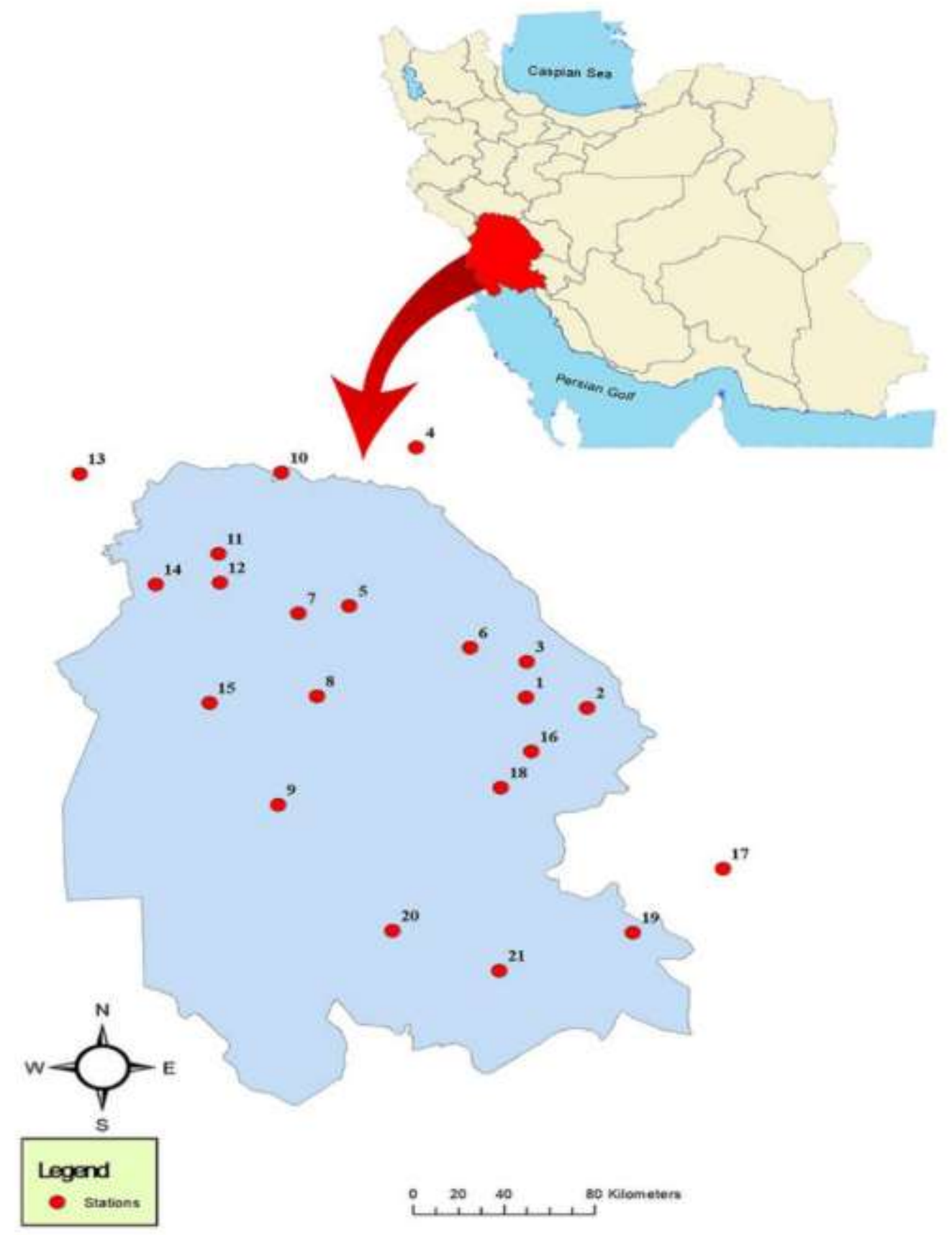

Figure 1. Map of the study area with location of the rainfall stations. 


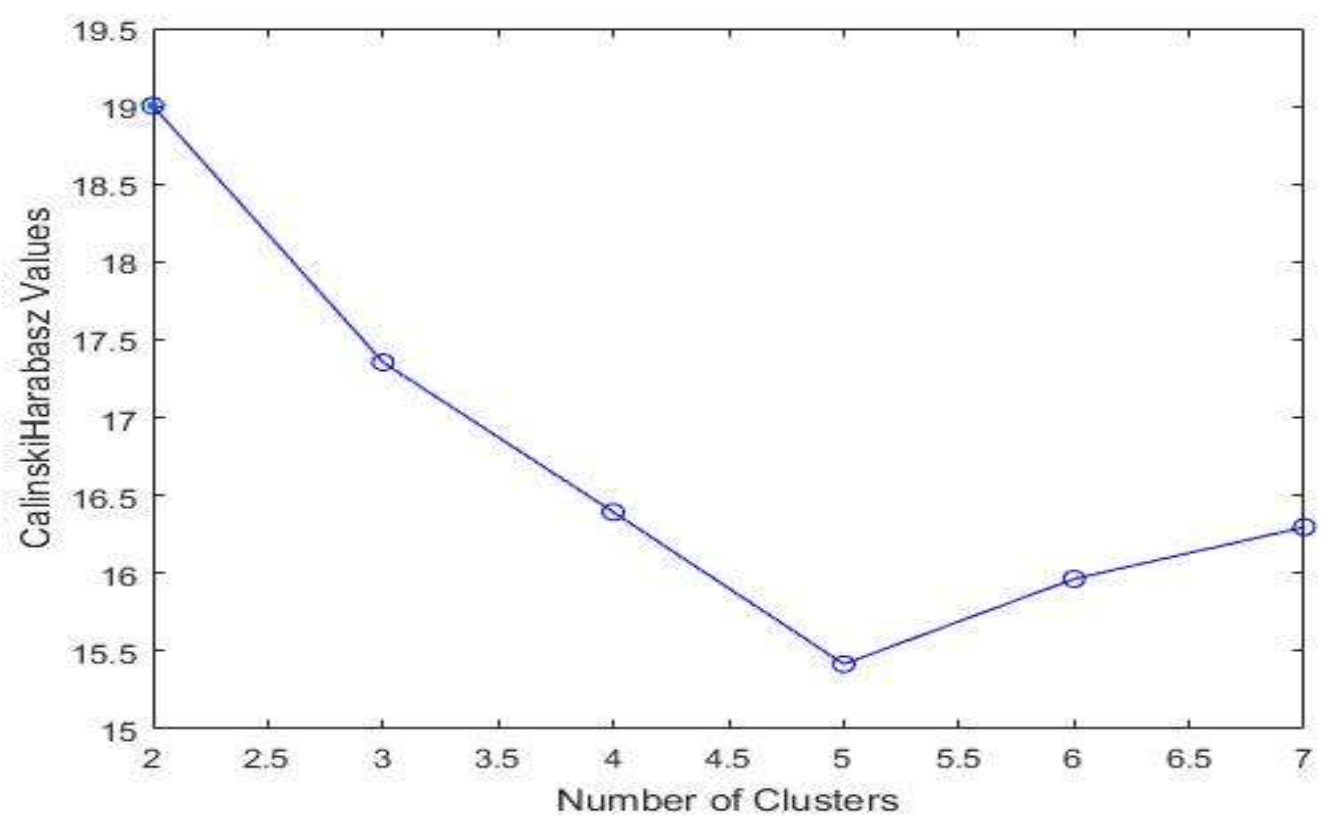

Figure 2. Calinsky-Harabasz values versus the number of clusters.

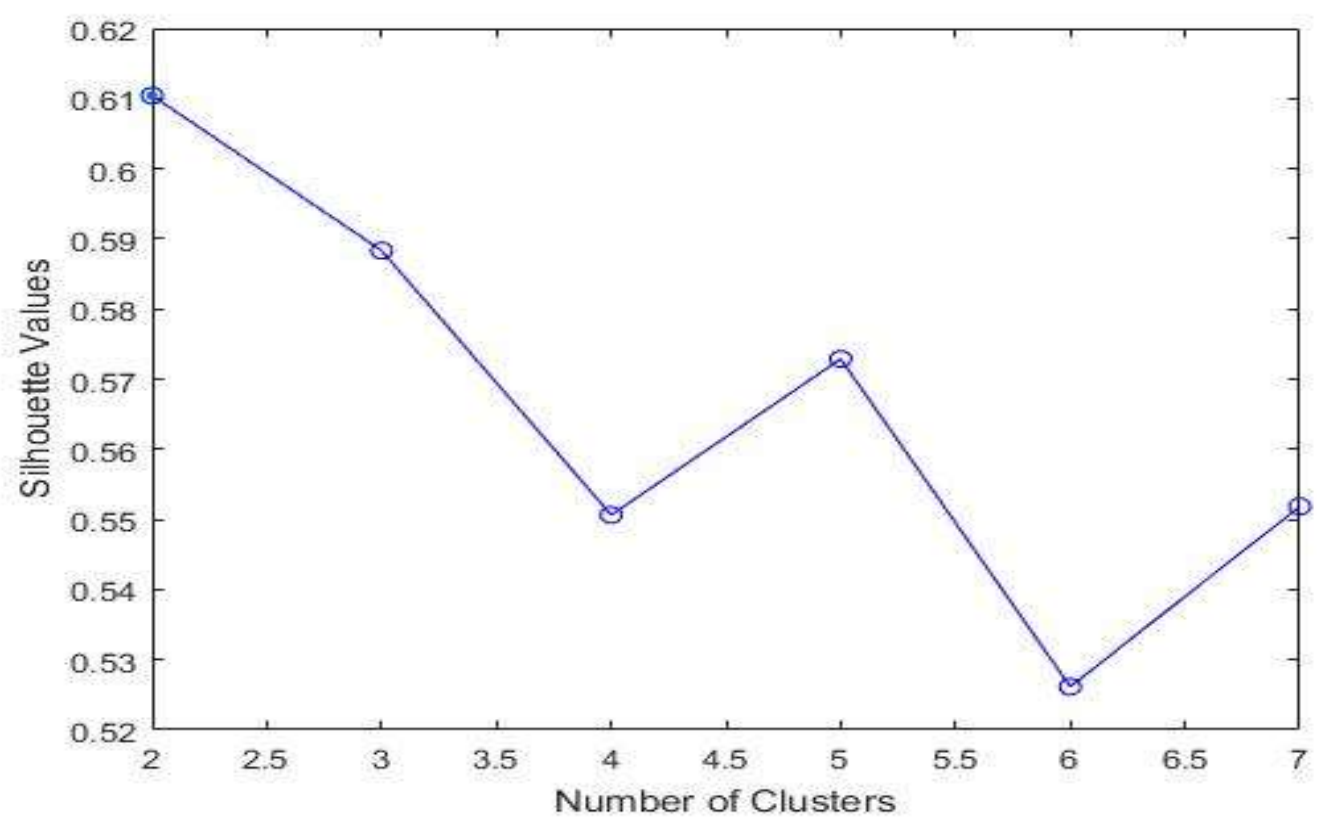

Figure 3. Sillhouette values versus the number of clusters. 


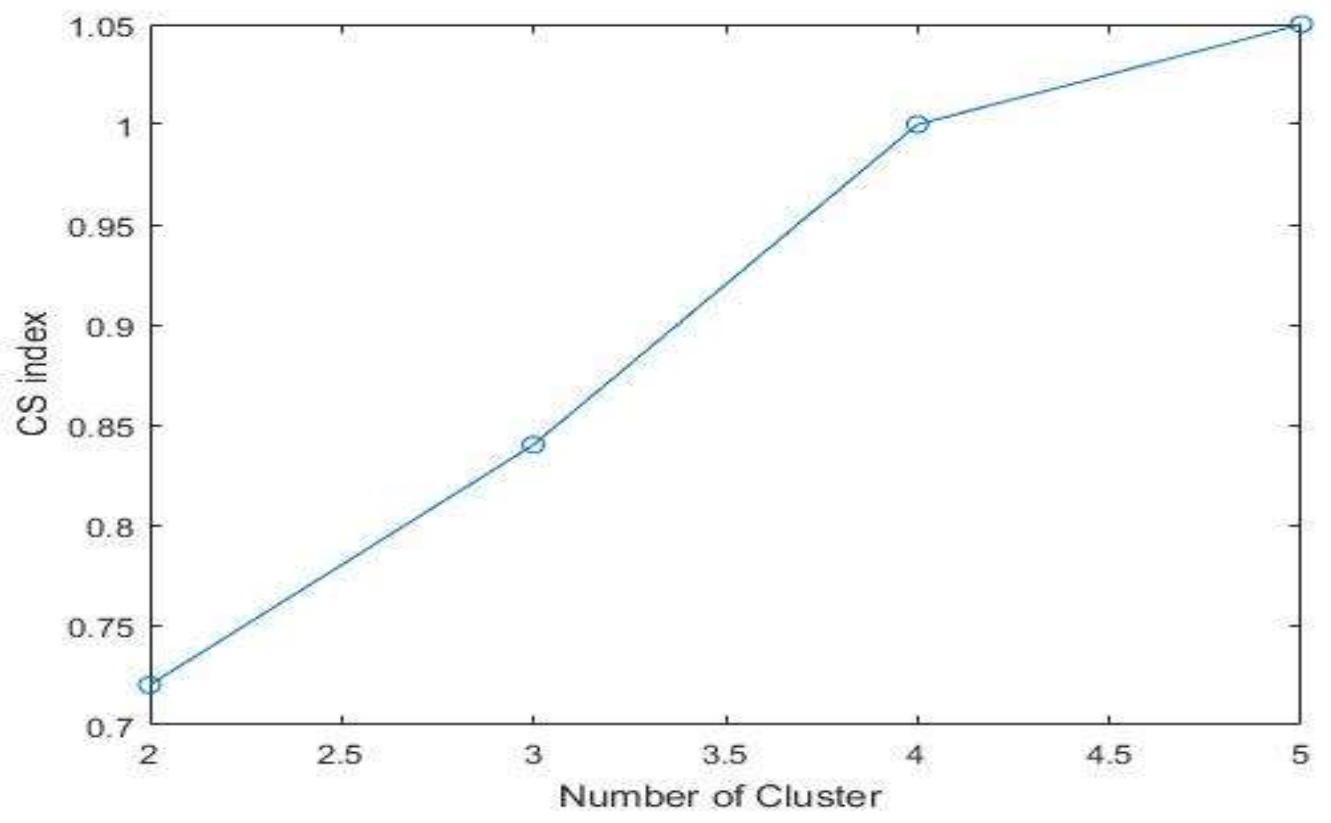

Figure 4. CS values versus the number of clusters.

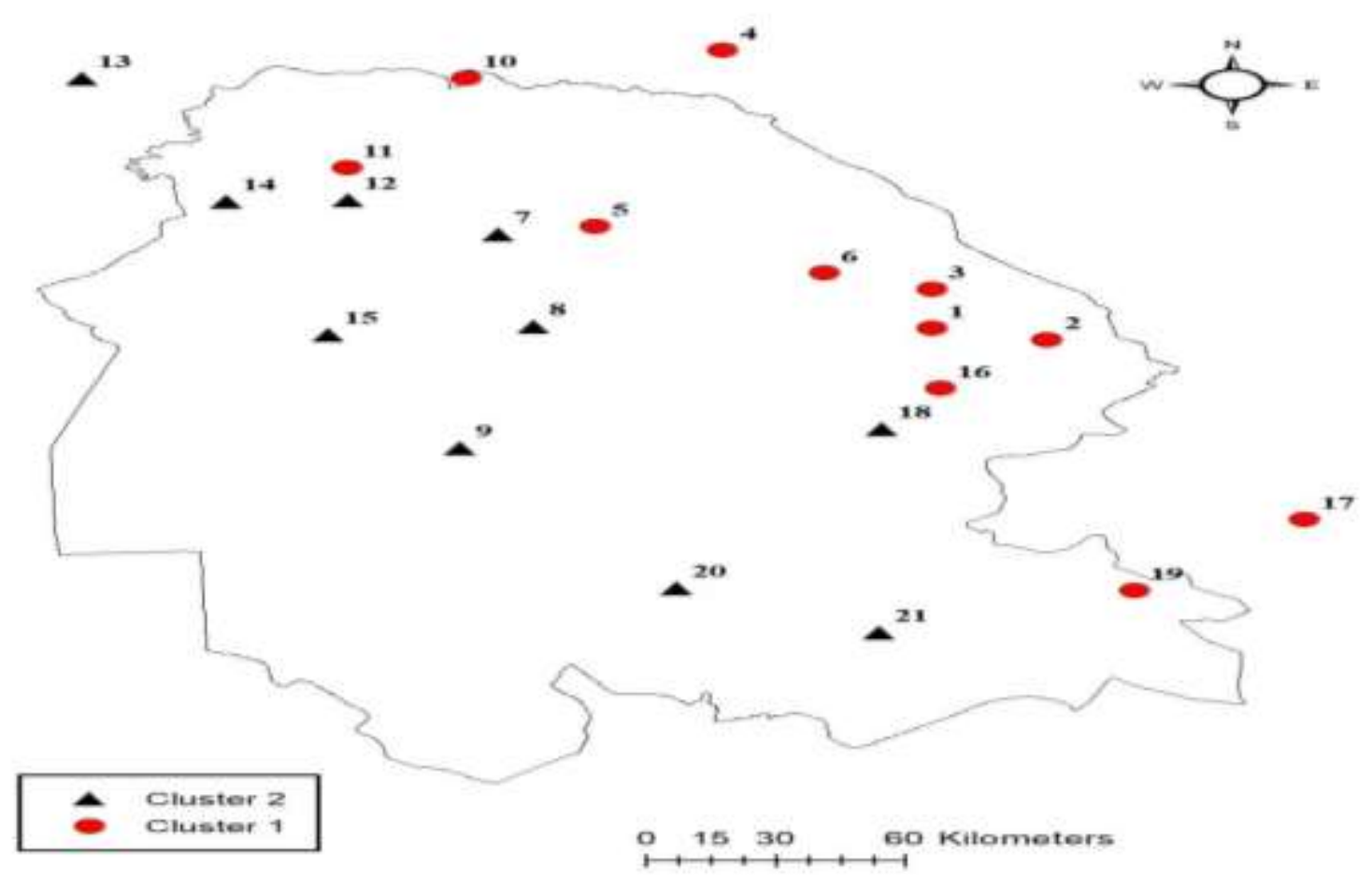

Figure 5. Location of stations in the cluster identified by NG. 


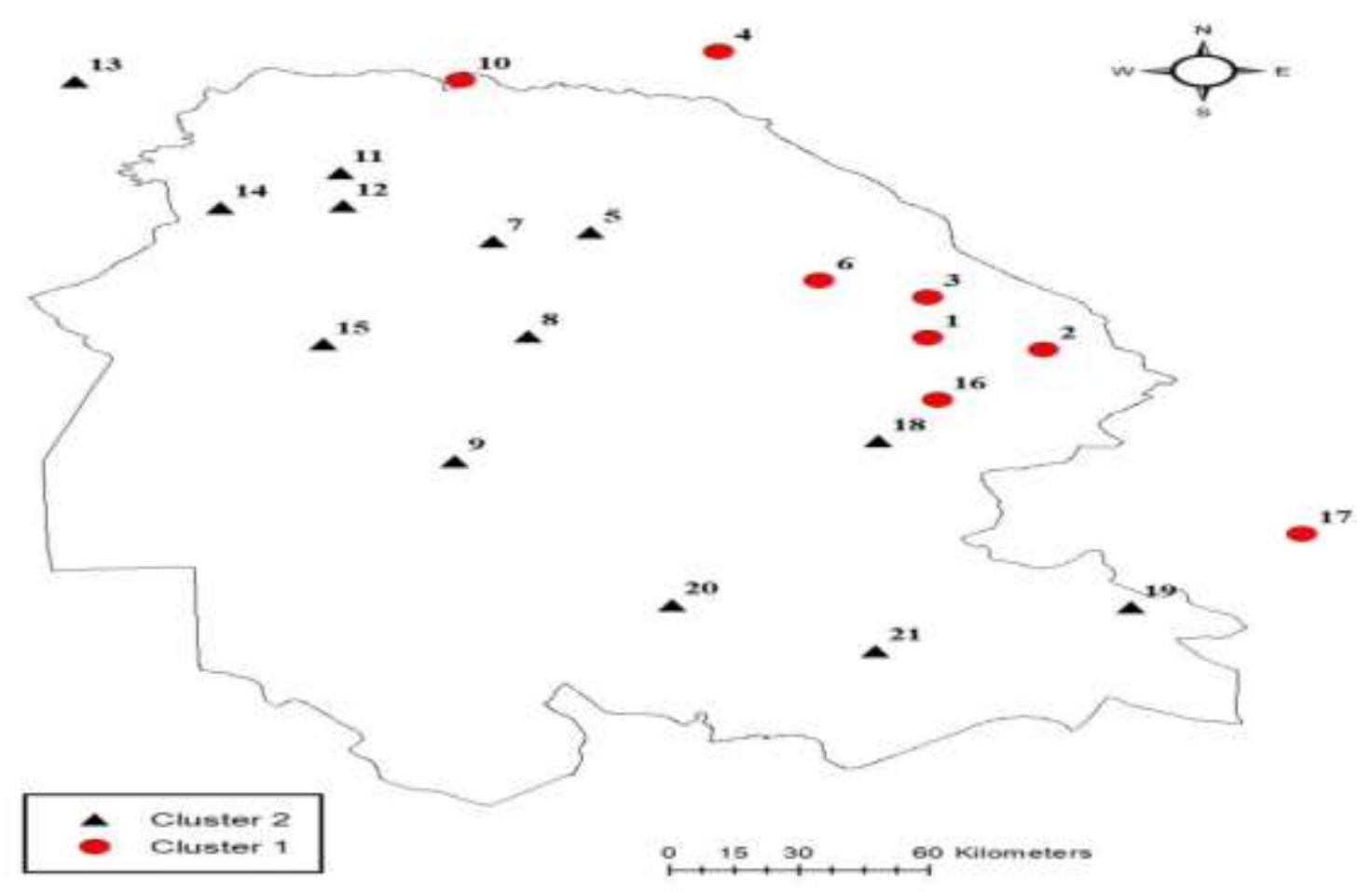

Figure 6. Location of stations in the cluster identified by GNG.

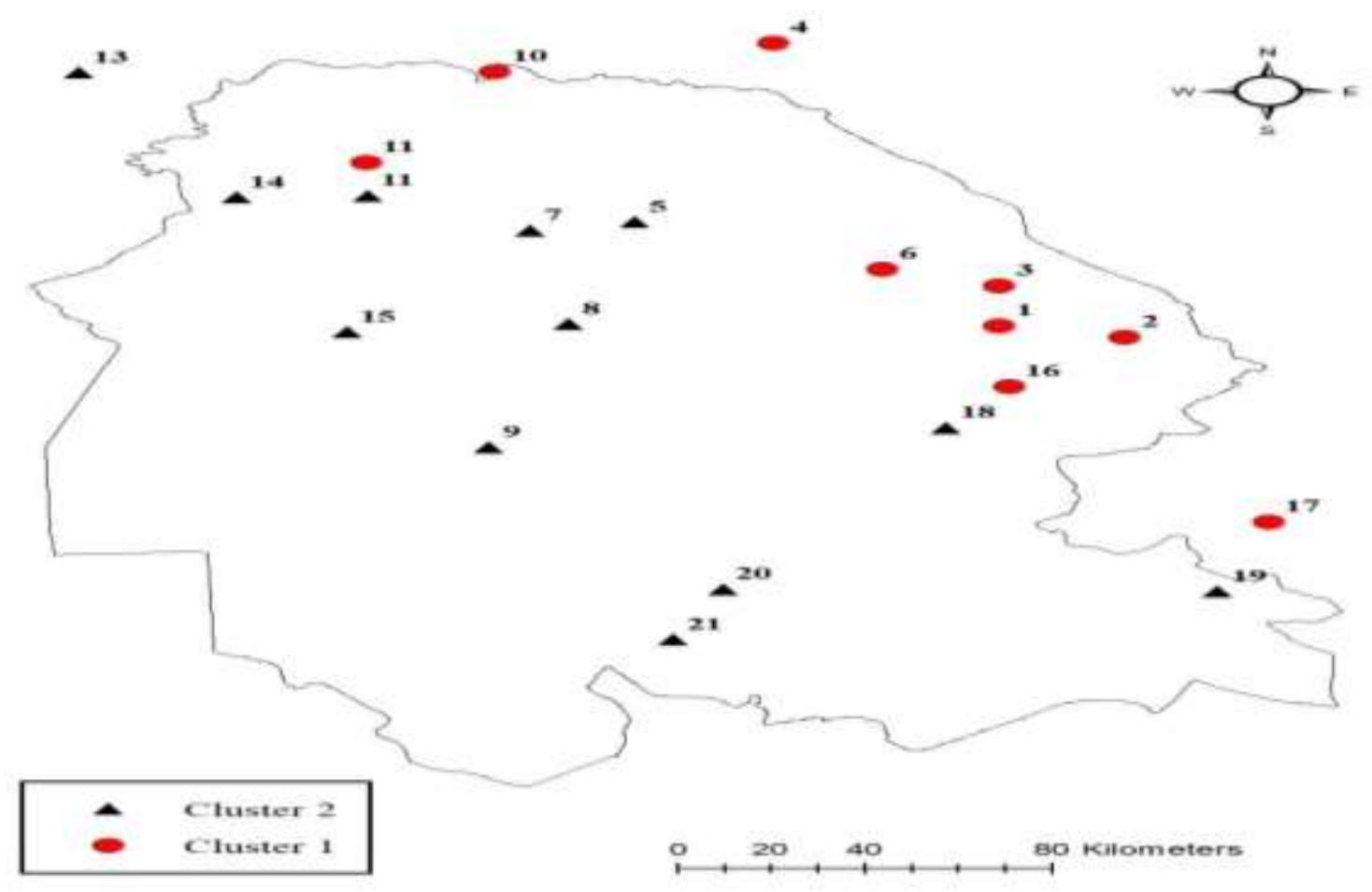

Figure 7. Location of stations in the cluster identified by SOM, K-Means, and Ward methods. 


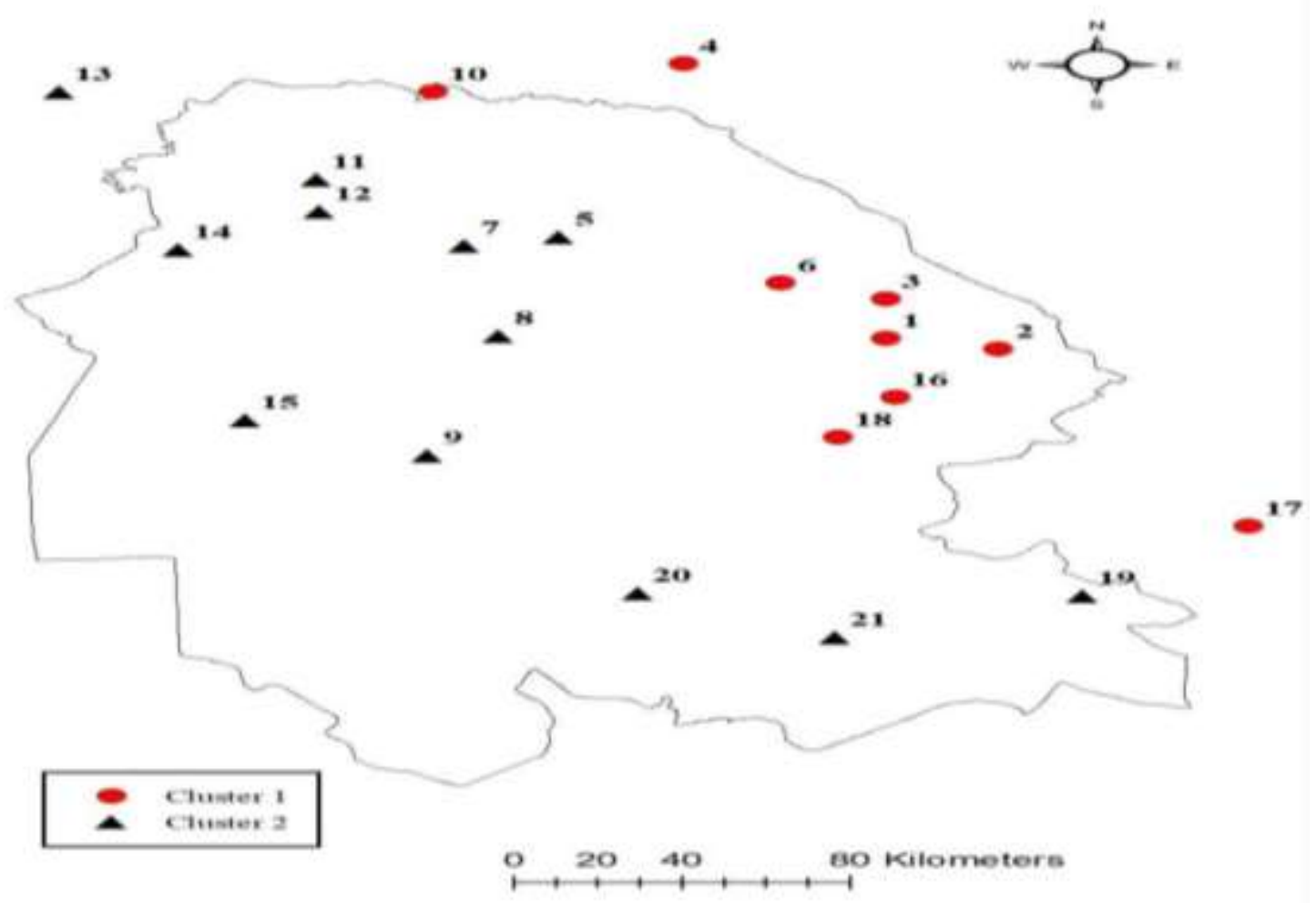

Figure 8. Location of stations in the cluster identified by FCM methods. 

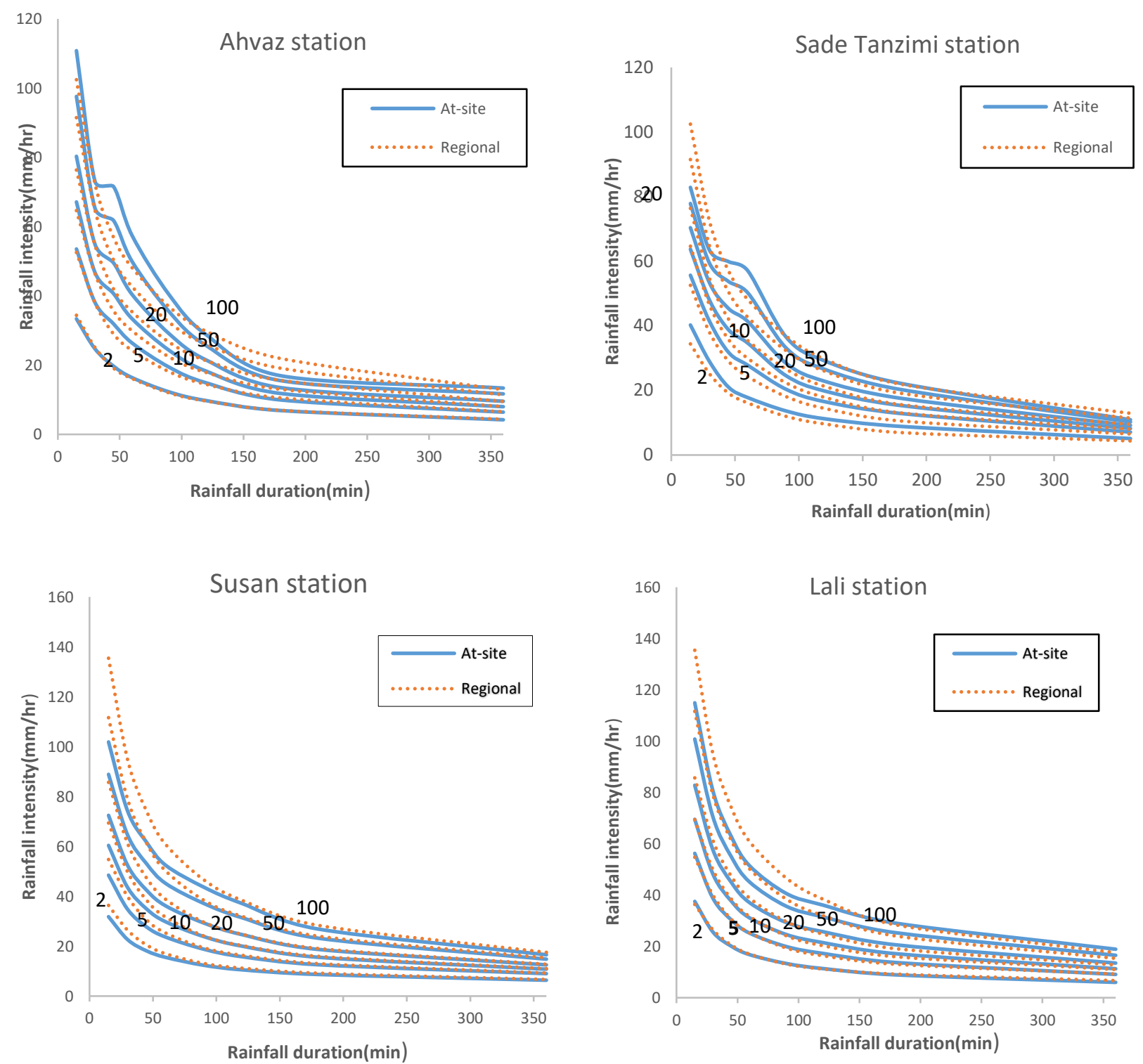

Figure 9. IDF curves for four rainfall stations in Khozestan province (Note: The values on each curve is the return period $\mathrm{T}$ for the curve). 


\section{Table captions}

Table 1. Attributes considered in this study

\begin{tabular}{|c|c|c|c|c|c|c|c|}
\hline $\begin{array}{l}\text { Station } \\
\text { number }\end{array}$ & Station name & Elevation (m) & Latitude & Longitude & MAP (mm) & $\mathrm{MDP}(\mathrm{mm})$ & $\begin{array}{l}\text { Record length } \\
\text { (Years) }\end{array}$ \\
\hline 1 & Izeh & 764 & $31^{\circ} 49^{\prime}$ & $49^{\circ} 51^{\prime}$ & 603.7 & 5.5 & 32 \\
\hline 2 & Pole Shalu & 700 & $31^{\circ} 45^{\prime}$ & $50^{\circ} 08^{\prime}$ & 762.8 & 6.7 & 30 \\
\hline 3 & Susan & 600 & $31^{\circ} 59^{\prime}$ & $49^{\circ} 52^{\prime}$ & 766.6 & 6.1 & 31 \\
\hline 4 & Andika & 500 & $33^{\circ} 02^{\prime}$ & $49^{\circ} 24^{\prime}$ & 547.7 & 6.2 & 22 \\
\hline 5 & Lali & 150 & $32^{\circ} 17^{\prime}$ & $49^{\circ} 03^{\prime}$ & 425.1 & 3.6 & 26 \\
\hline 6 & Abasspoor & 820 & $32^{\circ} 04^{\prime}$ & $49^{\circ} 36^{\prime}$ & 552 & 5.1 & 32 \\
\hline 7 & Gotvand & 75 & $32^{\circ} 15^{\prime}$ & $48^{\circ} 49^{\prime}$ & 384.5 & 4.7 & 31 \\
\hline 8 & Arabhasan & 33 & $31^{\circ} 51^{\prime}$ & $48^{\circ} 53^{\prime}$ & 269.2 & 3 & 28 \\
\hline 9 & Ahvaz & 20 & $31^{\circ} 20^{\prime}$ & $48^{\circ} 41^{\prime}$ & 219.4 & 4 & 42 \\
\hline 10 & Tange Panj & 540 & $32^{\circ} 56^{\prime}$ & $48^{\circ} 46^{\prime}$ & 1140 & 8.3 & 23 \\
\hline 11 & Sade Dez & 525 & $32^{\circ} 33^{\prime}$ & $48^{\circ} 27^{\prime}$ & 476.2 & 5.3 & 31 \\
\hline 12 & Sade Tanzimi & 142 & $32^{\circ} 25^{\prime}$ & $48^{\circ} 27^{\prime}$ & 362.9 & 3.9 & 28 \\
\hline 13 & Chamgaz & 38 & $32^{\circ} 57^{\prime}$ & $47^{\circ} 49^{\prime}$ & 481.3 & 4.8 & 26 \\
\hline 14 & Paye pol & 90 & $32^{\circ} 25^{\prime}$ & $48^{\circ} 09^{\prime}$ & 293.9 & 4.3 & 16 \\
\hline 15 & Abdolkhan & 40 & $31^{\circ} 50^{\prime}$ & $48^{\circ} 23^{\prime}$ & 226.9 & 3.7 & 31 \\
\hline 16 & Bagh Malek & 675 & $31^{\circ} 33^{\prime}$ & $49^{\circ} 52^{\prime}$ & 563.9 & 6.4 & 39 \\
\hline 17 & Idanak & 560 & $30^{\circ} 57^{\prime}$ & $50^{\circ} 25^{\prime}$ & 617 & 8.3 & 29 \\
\hline 18 & Machin & 380 & $31^{\circ} 23^{\prime}$ & $49^{\circ} 43^{\prime}$ & 372.2 & 4.9 & 25 \\
\hline 19 & Sade Shohada & 333 & $30^{\circ} 40^{\prime}$ & $50^{\circ} 17^{\prime}$ & 340.8 & 3.8 & 42 \\
\hline 20 & Kamp Jarahi & 8 & $30^{\circ} 43^{\prime}$ & $49^{\circ} 11^{\prime}$ & 187.6 & 3.1 & 24 \\
\hline 21 & Dehmolla & 32 & $30^{\circ} 30^{\prime}$ & $49^{\circ} 40^{\prime}$ & 220.6 & 3.7 & 31 \\
\hline
\end{tabular}


Table 2. Employed parameters in the NG and GNG

\begin{tabular}{cccccccc}
\hline Model & \multicolumn{1}{c}{ Parameters } \\
\hline $\mathrm{Ng}$ & $T_{i}=5$ & $T_{f}=1$ & $t_{\max }=10000$ & $\varepsilon_{i}=0.9$ & $\varepsilon_{f}=0.001$ & $\lambda_{i}=1$ & $\lambda_{f}=0.5$ \\
$\mathrm{GNG}$ & $\mathrm{T}=50$ & $\mathrm{~L}=40$ & $\mathrm{~d}=0.995$ & $\alpha=0.5$ & $\varepsilon_{\mathrm{n}}=0.0006$ & $\varepsilon_{\mathrm{b}}=0.05$ \\
\hline
\end{tabular}

Table 3. Results of heterogeneity and discordancy measures for 24-hr rainfall duration

\begin{tabular}{|c|c|c|c|c|c|c|c|}
\hline \multirow{2}{*}{ Cluster } & \multirow{2}{*}{$\begin{array}{c}\text { Clustering } \\
\text { models }\end{array}$} & \multirow{2}{*}{$\begin{array}{c}\text { Number of } \\
\text { stations }\end{array}$} & \multirow{2}{*}{$\begin{array}{l}\text { Discordant } \\
\text { stations }\end{array}$} & \multicolumn{3}{|c|}{ Heterogeneity measure } & \multirow{2}{*}{$\begin{array}{l}\text { Heterogeneity } \\
\text { situation }\end{array}$} \\
\hline & & & & $\mathrm{H}_{1}$ & $\mathrm{H}_{2}$ & $\mathrm{H}_{3}$ & \\
\hline \multirow{6}{*}{1} & NG & 11 & - & -1.12 & -1.13 & -1.04 & $\begin{array}{c}\text { Definitely } \\
\text { homogeneous }\end{array}$ \\
\hline & GNG & 8 & - & -0.91 & -1.91 & -1.63 & $\begin{array}{c}\text { Definitely } \\
\text { homogeneous }\end{array}$ \\
\hline & SOM & 9 & - & -1.11 & -2.01 & -1.81 & $\begin{array}{c}\text { Definitely } \\
\text { homogeneous }\end{array}$ \\
\hline & FCM & 9 & - & -0.64 & -1.79 & -1.59 & $\begin{array}{c}\text { Definitely } \\
\text { homogeneous }\end{array}$ \\
\hline & K-means & 9 & - & -1.11 & -2.01 & -1.81 & $\begin{array}{c}\text { Definitely } \\
\text { homogeneous }\end{array}$ \\
\hline & Ward & 9 & - & -1.11 & -2.01 & -1.81 & $\begin{array}{c}\text { Definitely } \\
\text { homogeneous }\end{array}$ \\
\hline \multirow{6}{*}{2} & NG & 10 & - & 0.17 & -1.28 & -2.33 & $\begin{array}{c}\text { Definitely } \\
\text { homogeneous }\end{array}$ \\
\hline & GNG & 13 & - & 0.23 & -0.12 & -1.3 & $\begin{array}{c}\text { Definitely } \\
\text { homogeneous }\end{array}$ \\
\hline & SOM & 12 & - & 0.39 & -0.04 & -1.21 & $\begin{array}{c}\text { Definitely } \\
\text { homogeneous }\end{array}$ \\
\hline & FCM & 12 & - & 0.12 & -0.01 & -1.09 & $\begin{array}{c}\text { Definitely } \\
\text { homogeneous }\end{array}$ \\
\hline & K-means & 12 & - & 0.39 & -0.04 & -1.21 & $\begin{array}{c}\text { Definitely } \\
\text { homogeneous }\end{array}$ \\
\hline & Ward & 12 & - & 0.39 & -0.04 & -1.21 & $\begin{array}{c}\text { Definitely } \\
\text { homogeneous }\end{array}$ \\
\hline
\end{tabular}

Table 4. Estimated parameters of GEV and GLOG distributions as the regional probability distributions of annual maximum storm intensities for two regions in the NG model

\begin{tabular}{ccc|cccc}
\hline \multicolumn{3}{c}{ Cluster 2 (GEV) } & \multicolumn{5}{c}{ Cluster 1 (GLOG) } & \multirow{2}{*}{$\mathrm{d}$ (minute) } \\
\cline { 1 - 6 } $\mathrm{U}$ & $\alpha$ & $\mathrm{K}$ & $\varepsilon$ & $\alpha$ & $\mathrm{K}$ & \\
\hline 0.7542 & 0.4257 & -0.0002 & 0.8744 & 0.2624 & -0.2672 & 15 \\
0.7607 & 0.4258 & 0.0115 & 0.8836 & 0.2674 & -0.2464 & 30 \\
0.7571 & 0.4123 & -0.0119 & 0.8792 & 0.2582 & -0.2621 & 45 \\
0.7574 & 0.4040 & -0.0230 & 0.8808 & 0.2547 & -0.2621 & 60 \\
0.7552 & 0.3892 & -0.0499 & 0.8810 & 0.2489 & -0.2669 & 90 \\
0.7568 & 0.3762 & -0.0657 & 0.8867 & 0.2451 & -0.2595 & 120 \\
0.7544 & 0.3728 & -0.0766 & 0.9077 & 0.2366 & -0.2235 & 180 \\
0.7622 & 0.3930 & -0.0276 & 0.9426 & 0.2334 & -0.1458 & 360 \\
0.7635 & 0.4183 & 0.0121 & 0.9721 & 0.2402 & -0.0701 & 720 \\
0.7548 & 0.4243 & -0.0007 & 09646 & 0.2553 & -0.0837 & 1080 \\
0.7756 & 0.4117 & 0.0337 & 0.9621 & 0.2533 & -0.0901 & 1440 \\
\hline
\end{tabular}


Table 5. Average values of goodness-of-fit indices of the difference between IDF curves based on regional and at-site probability distributions for the used clustering models

\begin{tabular}{cccc} 
& \multicolumn{3}{c}{ Values of goodness of fit indices } \\
\cline { 2 - 4 } Model & $\mathrm{CV}_{\text {RMSE }}$ & $\Delta$ & MBE \\
\hline NG & 24.39 & 15.56 & -0.04 \\
GNG & 24.41 & 16.03 & 0.23 \\
FCM & 25.19 & 16.35 & 0.32 \\
SOM, K-Means, Ward & 24.67 & 15.91 & 0.31 \\
\hline
\end{tabular}

Table 6. Values for goodness-of-fit indices of the difference between IDF curves based on regional and at-site probability distributions at 21 rainfall stations for the NG clustering model

\begin{tabular}{cccc}
\hline \multirow{2}{*}{ Stations } & \multicolumn{3}{c}{ Values of goodness-of-fit indices } \\
\cline { 2 - 4 } & $\mathrm{CV}_{R M S E}$ & MBE & $\Delta$ \\
\hline 1 & 29.46 & -2.11 & 10.75 \\
2 & 42.46 & -6.61 & 24.84 \\
3 & 26.38 & -2.89 & 11.67 \\
4 & 14.68 & -1.42 & 10.04 \\
5 & 15.61 & -1.77 & 9.14 \\
6 & 23.07 & -2.05 & 8.51 \\
7 & 17.49 & 0.28 & 14.29 \\
8 & 23.38 & -0.11 & 10.32 \\
9 & 13.59 & 1.43 & 5.91 \\
10 & 21.3 & 6.85 & 28.14 \\
11 & 18.67 & 1.58 & 8.33 \\
12 & 16.27 & 0.80 & 13.06 \\
13 & 23.36 & -1.38 & 20.99 \\
14 & 46.52 & 9.48 & 28.56 \\
15 & 27.05 & -2.34 & 14.41 \\
16 & 26.02 & -3.71 & 18.87 \\
17 & 29.19 & 0.27 & 19.62 \\
18 & 15.55 & 2.13 & 22.00 \\
19 & 35.81 & -3.70 & 21.42 \\
20 & 30.17 & 5.12 & 14.33 \\
21 & 16.11 & -0.69 & 11.72 \\
Average & $\mathbf{2 4 . 3 9}$ & $\mathbf{- 0 . 0 4}$ & $\mathbf{1 5 . 5 6}$ \\
\hline
\end{tabular}

